\title{
Social Isolation and Weapon Use in Intimate Partner Violence Incidents in Rural Areas ${ }^{1}$
}

\author{
Michael O. Maume \\ Professor \\ Department of Sociology and Criminology \\ University of North Carolina Wilmington \\ 601 S. College Rd. \\ Wilmington, NC 28403-5978 \\ Christina L. Lanier \\ Associate Professor \\ Department of Sociology and Criminology \\ University of North Carolina Wilmington \\ 601 S. College Rd. \\ Wilmington, NC 28403-5978 \\ Leslie H. Hossfeld \\ Professor \\ Department of Sociology and Criminology \\ University of North Carolina Wilmington \\ 601 S. College Rd. \\ Wilmington, NC 28403-5978 \\ Kyle Wehmann, MA \\ Colorado West Regional Mental Health, Inc. \\ PO Box 6807 \\ Breckenridge, $\mathrm{CO} 80424$ \\ Contact author - Michael O. Maume: maume@uncw.edu; 19109627749
}

\begin{abstract}
This study relies on the concept of social isolation to analyze variation in weapon use in intimate partner violence (IPV) cases in rural North Carolina. Social isolation and IPV weapon use are operationalized through census and IPV incident data collected in three rural counties in southeastern North Carolina. The authors relied on reports of IPV from law enforcement agencies within these counties, which were geocoded by address and located within census tracts to assess IPV weapon use and its correlates across sub-county areas. The current study expands on studies of weapon use and social isolation by criminologists and public health researchers by assessing the nature of IPV incidents, accounting for possible incident-level and contextual correlates. Statistical analyses indicate that sex of the attacker (female) and age are the only significant predictors of weapon use. We discuss the implications of these findings for further research on weapon use and IPV in rural areas.

Keywords: Social Isolation; Intimate Partner Violence; Rural Communities; Weapon Use; Police Data
\end{abstract}


Social Isolation and Weapon Use in Intimate Partner Violence Incidents in Rural Areas - Maume, Lanier, Hossfeld, and Wehmann

\section{Introduction}

Intimate partner violence, or IPV, is a longstanding criminal and public health concern in the United States. It is estimated that at least 25 percent of all women living in the U.S. will be abused two or more times by a male partner during their lifetime, and "domestic violence continues to be the largest cause of injury and death to American women each year." (Eastman et al. 2007, p. 700). The statistic is astounding, yet despite its widespread occurrence much of the research on IPV continues to focus on urban settings, overlooking the unique experiences of abused rural women. Current research suggests that IPV rates are similar in urban and rural areas (DeKeseredy, Dragiewicz and Rennison, 2012); however, despite the equivalent nature of its occurrence, rural IPV has seen a profound lack of attention and documentation. There are two sets of findings that prompt a focus on rural areas. First is the research on the homicide decline. While a portion of the decline in U.S. homicide rates since the early 1990's has been attributed to an overall decline in intimate partner homicide, recent research has disaggregating urban and rural trends reveal that intimate partner homicide rates not only did not decline, but increased by 60 percent over the 1980's and 1990's (Gallup-Black, 2005; Jennings and Piquero, 2008). Second, qualitative studies of IPV in rural areas have revealed that both the structure and culture of rural environments may help both engender and conceal a particular type of violence against women (Websdale, 2002; DeKeseredy and Schwartz, 2009). Some researchers have found that women in rural areas reported a higher incidence of hair-pulling, torture, and being shot at by the abuser. So, besides the need to examine the level of IPV in rural areas, particularly with regard to homicide, research also suggests the need to further examine how the quality, or nature, of violence differs in rural areas.

The purpose of this study was to assess the nature of IPV in rural southeastern North Carolina; specifically, the prevalence of weapon use in violent intimate-partner incidents in three rural counties, and factors that may explain such use. Following a review of issues specific to IPV in rural areas, we focus attention on social isolation as a contextual concept that is particularly suited to explaining IPV in rural areas, and weapon use as a qualitative outcome in research on rural IPV. The study involved analysis of incident records collected from several law enforcement agencies in rural southeastern North Carolina, and analyses that follow are based on information on incident gathered from these reports, as well as contextual data on the communities where the IPV incidents occurred. There have been only a handful of studies that examined weapon use in IPV incidents (Kernsmith and Craun, 2008; Folkes, Hilton and Harris, 2013), and none that have taken the social ecological context into account. In addition, there are few quantitative studies of IPV that have employed agency-based data relative to survey-based data, particularly using data provided from police reports (Addington and Perumean-Chaney, 2013; Capaldi, Shortt, Kim, Wilson, Crosby and Tucci, 2009; Warner, 2010). 


\section{Review of the Literature}

\section{Explaining Rural Intimate Partner Violence}

Because the focus of this study was on how the nature of violence is different in rural areas, and more explicitly how IPV differs within and between rural areas, it relied in part on ecological explanations of violence (Pinchevsky and Wright, 2012; Capaldi, Knoble, Shortt and Kim, 2012). Within small community contexts, social disorganization theory has been used to inform ecological studies of violence. Social disorganization is defined as "the inability of a local community to regulate itself in order to attain goals that are agreed to by the residents of that community" (Bursik, 1988, p.525). This contemporary definition has taken the theory in two directions. The first is a continued emphasis on the key role of neighborhood organizations in keeping crime victimization at low levels (Peterson et al, 2000; Triplett et al, 2003), while the second has involved a focus on the importance of effective social ties and social support, or lower levels of social isolation within communities (Benson, Fox and DeMaris, 2003; Sampson and Groves, 1989; Sampson, Raudenbush and Earls,1997). The two directions have in common the principle that communities that are socially disorganized tend to have more serious problems of violence and crime, and rural communities are no exception (Osgood and Chambers, 2000). Studies of IPV applying social disorganization concepts have shown that women living in neighborhoods with above-average levels of economic deprivation or below-average levels of collective efficacy (i.e., social ties and social support) were significantly more likely to be victimized by their partners than women living in more economically advantaged neighborhoods (Benson et al, 2003; Miles-Doan, 1998; Browning, 2002). In addition, a multilevel study by Li and colleagues using police reports of domestic violence found an elevated risk of IPV for women living in neighborhoods characterized by high rates of poverty and unemployment and relatively low rates of educational attainment, although the findings were stronger for White and Latino women than for Black women (Li, Kirby, Sigler, Hwang, LaGory and Goldenberg, 2010). The implication is that efforts to inhibit partner violence should include policies designed to ameliorate local economic disadvantages and isolation from one's neighbors.

Additionally, feminist approaches have focused on (rural) patriarchy as an important ecological context for IPV. Social isolation is a key concept from this standpoint as well. In a study of battered women in rural Kentucky, Websdale (2002) described rural households as being isolated in two senses. The first and most obvious is geographic isolation, which has implications for intensifying the hidden nature of the violence itself and mitigating efforts to both seek and provide help. The second type of isolation referred to is sociocultural, or social. Websdale argues that "rural family life, gender roles, and patriarchal ideology generate acute forms of sociocultural isolation that render rural women particularly vulnerable to battering and passive policing" (Websdale, 2002:84). The remoteness of the places in which some of these battered women live exacerbates this sociocultural isolation. Websdale and others (DeKeseredy and Joseph, 2006; DeKeseredy, Donnermeyer, Schwartz, Tunnell and Hall, 2007) have argued 
that this situation is made even worse by the generally impoverished conditions of rural areas and the lack of structural resources which are available to women in more affluent communities (e.g., health care, social services, transportation).

Victims of rural IPV experience multiple forms of isolation unique to rural areas that contribute to the violence perpetrated against them. "Geographic and social isolation make many common problems such as poverty and domestic violence even more devastating to rural women" (Olsen, 1988, p. 5). An extremely remote address helps to keep abuse hidden away from the rest of the world. There may be no phone(s) in the home or neighbors close enough to witness/hear the abuse or run to for help. Possession of a driver's license or access to a vehicle or public transportation might be limited or none at all. Abusive partners might deny use of the car, disable it or closely monitor the mileage (Goeckermann, Hamberger and Barber, 1994; Websdale and Johnson, 1998; Schaffer, 1999). They may also inspect phone bills, incoming/outgoing mail or anything else that could indicate a cry for help. Victims have been known to be denied/forbidden contact with relatives, friends or the greater community (Feyen, 1989; Geissinger, Lazzari, Porter and Tungate, 1993; Goeckermann et al, 1994; Websdale, 1998).

Although the role of isolation in rural areas has been examined, researchers have tended to focus on the effect of geographic isolation on IPV as it relates to such issues as access to providers and services. While this type of isolation is important, it is also essential to examine how social isolation (defined above), or a lack of collective efficacy in rural communities, may contribute to violence among intimates (Lanier and Maume, 2009) and the difficulties faced by battered partners seeking to leave violent relationships (DeKeseredy and Schwartz, 2009). Another common characteristic of rural areas is that they are economically disadvantaged. "Poverty rates among people living in rural communities are higher than in urban populations across all ethnic and racial groups" (Krishnan, Hilbert and VanLeeuwen, 2001, p. 36). Being mostly traditional, single-industry economies (i.e., farming, mining or manufacturing), rural areas are hit hard by economic hardship in the form of job loss (displaced workers), unemployment, poverty and population loss (Lee, Maume, and Ousey, 2003; Hossfeld, Legerton and Keuster, 2004; Gallup-Black, 2005). From a theoretical standpoint, we argue that social disorganization/collective efficacy and feminist/rural patriarchy approaches share the concept of social isolation as a key factor in understanding violence in rural areas. We argue that social isolation should not only influence the extent of IPV, but the nature of such incidents as well (Thomas, 2009). We now turn to studies that have examined weapon use as a significant issue in IPV incidents.

\section{Weapon Use and IPV}

The majority of quantitative IPV studies have relied on analyses of survey data, and in particular analyses of the extent of IPV, as well as differences and explanations for differences in the extent of IPV. A whole host of sociological and criminological theories has been brought to 
bear on studies of e.g., spousal homicide, date rape, and many other types of violence involving intimate partners. As discussed above, our approach is similar to those who have taken a contextual or ecological perspective; however, rather than focusing on explaining the extent of IPV within and across social areas, our focus is this study is on the nature of IPV, and in particular a quantitative assessment of weapon use in IPV incidents in rural areas.

As Sorenson (2006) noted in a recent review, while there have been many studies of the role of weapon accessibility and use in criminal violence, and many, many more studies of IPV, there have been only a handful of studies that examined weapon use in IPV incidents. Weapons have been found to escalate the use of violence to resolve conflicts (Phillips and Maume, 2007; Wells and Horney, 2002), and a review of weapon use in IPV incidents found that the presence of firearms in the household significantly increases the odds of an IPV incident becoming fatal (Wilkinson and Hammerschlag, 2005). Sorenson (2006) found that where firearms are employed by intimate partners, they are more likely to be used against women, although she notes that less than one percent of IPV incidents result in a fatality. The use of weapons - and firearms in particular - in non-lethal IPV incidents is rare compared to violent incidents involving acquaintances and strangers, with prevalence rates well below 10 percent in both the United States and Canada (Folkes et al, 2013; Sorenson and Wiebe, 2004). Analyses of both general survey and agency-based data have found that women are more likely than men to yield weapons in IPV incidents. Brennan and Moore (2009) reported on an analysis of IPV incidents which indicated that women were three times likelier to use a weapon against a partner than were men. In one of the few studies focused on predicting weapon use in IPV incidents, Kernsmith and Craun (2008) found that suspect gender (female) and the presence of a restraining order were the only variables that differentiated cases where weapons were and weren't used. Their study was based on a sample of 385 domestic violence police reports from San Diego - a large urban county - and did not take the social context of IPV into account.

Even fewer studies have examined the role of weapons in incidents of intimate partner violence in rural areas. In their comparison of abused and non-abused women in rural Georgia, Shuman and colleagues found that while the prevalence of gun ownership did not differ between the two groups, abused women reported significantly higher rates of their partner carrying a weapon such as a gun or knife (Shuman, McCauley, Waltermaurer, Roche, Hollis, Kilgannon, Denver, Jones and McNutt, 2008). Similarly, Teaster, Roberto, and Dugar's (2006) qualitative study of older rural women experiences with intimate partner violence revealed a high rate of the use or threat of weapons, particularly guns and knives. They noted that "many women had lived their entire lives around guns" and the respondents "...described men as having an 'arsenal' of weapons..." (Teaster et al, 2006, p 644). Thus, these studies suggest the use of weapons in rural intimate partner violence is an important issue for inquiry. ${ }^{2}$ 
Social Isolation and Weapon Use in Intimate Partner Violence Incidents in Rural Areas - Maume, Lanier, Hossfeld, and Wehmann

\section{Study Setting}

Southeastern North Carolina is a large rural region with two major urban centers: Wilmington and Fayetteville. Persistent poverty, low educational attainment, low income and enduring racial inequalities characterize the region, as does its remarkable racial diversity. Sixty-five percent of the 12-county region is white and African Americans comprise $28 \%$ of the region's population. Native Americans comprise 6 percent of the region's population. North Carolina has seen a dramatic surge in the immigrant Latino population, with an increase of almost 400\% between 1990 (76,726 Latinos) and 2000 (378,963) (Guzmán 2001). Four contiguous counties in the region are considered counties of persistent poverty by USDA measures (counties with over $20 \%$ poverty since 1970): Hoke, Robeson, Columbus and Bladen. The region has experienced massive textile and apparel manufacturing and agricultural job loss and has experienced little in terms of recovery.

Three rural counties in southeastern North Carolina were selected based on their racial and ethnic distributions: Robeson, Columbus, and Bladen. ${ }^{3}$ As noted above, these three counties are defined as persistent-poverty counties by the USDA, meaning that 20 percent or more of their populations were living in poverty over the last 30 years (measured by the 1980, 1990, and 2000 decennial censuses) (USDA ERS, 2013). Table 1 provides selected sociodemographic characteristics and violent crime statistics for the three counties, in comparison to North Carolina overall. The largest of the three counties, Robeson, which was classified as micropolitan in 2003 by U.S. Census Bureau, is also the most diverse, with White residents making up a statistical minority of the population. In addition, there is a sizeable Native American population made up of individuals claiming Lumbee tribal heritage, followed by Cherokee. In addition to high poverty rates, the three counties report higher rates of unemployment, welfare assistance, rented households, and vehicle-less households than the state as a whole. Violent crime rates (based on law enforcement reports) are significantly higher than the state average as well. The level of interpersonal violence has become a serious concern for criminal justice agencies and the population at large.

\section{Data and Methods}

The IPV incident data for the current study were collected as part of a pilot for a larger research project aimed at understanding the social dynamics of intimate partner violence across the region. Local law enforcement agencies in all three counties were contacted to request their permission to obtain records of all incidents pertaining to IPV that occurred in their jurisdictions between January 1, 2004 and December 31, 2007. ${ }^{4}$ Most of the reports listed two or three offenses per incident. The research team decided to use just the primary (most severe) offense for coding purposes. Offenses included attempted and completed misdemeanor and felony assaults, homicides, rape and sexual assault, domestic disturbances (e.g. violation of a DV protective 
order), and other violent crimes committed against an intimate partner. There were a total of 2,372 IPV-related incidents recorded by the research team.

Each of the IPV-related incidents that occurred in each county between 2004 and 2007 was geographically coded using the location (i.e., address) of the incident, and located within one of the 39 census tracts that make up these counties. In the United States, the census tract is a subdivision of a county that is populated by between 2,500 and 8,000 residents, with an average of 4,000. Tracts are further subdivided into block groups, which are aggregates of residential and commercial street blocks containing an average of 1,000 to 1,500 residents (U.S. Census Bureau 2001). Both tracts and block groups are commonly used as geographic contexts and proxies for neighborhoods in public health (Krieger et al, 2003) and criminological studies of IPV (Benson et al, 2003; Miles-Doan, 1998) in the U.S., although tracts are more commonly used, especially for incidents outside of metropolitan areas. Census tracts are an appropriate unit of analysis for examining IPV and neighborhood/community deprivation (Miles-Doan, 1998; Messer et al,

Table 1. Selected Characteristics of Study Setting

\begin{tabular}{lcccc}
\hline County & Bladen & Columbus & Robeson & NC \\
\hline \hline Total Population (2000) & 32,278 & 54,749 & 123,339 & $8,049,313$ \\
Population change 2000-2010 (\%) & 9.0 & 6.1 & 8.8 & 18.5 \\
Population Density 2000 (persons per sq mile) & 36.9 & 58.4 & 130.0 & 165.2 \\
\% Black & 37.9 & 30.9 & 25.1 & 21.6 \\
\% White & 57.2 & 63.4 & 32.8 & 72.1 \\
\% Latino & 3.7 & 2.3 & 4.9 & 4.7 \\
\% American Indian & 2 & 3.1 & 38 & 1.2 \\
\% rented households & 31.1 & 34.1 & 40.6 & 28.8 \\
\% at different address 5 years prior & 28.6 & 29.9 & 35.8 & 44.4 \\
\% single mother-headed households & 8.4 & 8.9 & 12.3 & 7.1 \\
\% below poverty level & 21.0 & 22.7 & 22.8 & 12.3 \\
\% unemployed & 5.6 & 7.7 & 9.6 & 5.2 \\
\% households without vehicle & 9.3 & 10.0 & 11.0 & 7.5 \\
\% households on public assistance & 5.6 & 5.1 & 6.1 & 2.8 \\
\% of HS dropouts & 30.5 & 34.3 & 17.2 & 21.8 \\
Median housing value (USD\$) & 65,200 & 76,100 & 66,100 & 108,300 \\
Violent Crime Rates (2004-2007 avg.) & 707.6 & 591.8 & 763.5 & 475.7 \\
\hline
\end{tabular}

Sources: US Census Summary File 1 (2000, 2010); Summary File 3 (2000); NC Crime Statistics (http://crimereporting.ncdoj.gov/) 
Social Isolation and Weapon Use in Intimate Partner Violence Incidents in Rural Areas - Maume, Lanier, Hossfeld, and Wehmann

2006). Neighborhood blocks or even smaller levels of aggregation may be more appropriate in urban areas due to the density of people living there. Issues of contiguity and spatial dependence (e.g., autocorrelation) are more likely a concern in denser areas as well. Rural IPV incidents can be so spread out that a rate of only one or two incidents recorded within several neighborhood blocks is likely, making the census tract contextual-level analysis more appropriate. Initial efforts to code the incidents within tracts resulted in about two-thirds of incidents successfully located within specific tracts. Unmatched addresses in each county were hand-matched to census tracts using other sources. These efforts identified a census tract location for 84 percent of IPVrelated incidents $(\mathrm{N}=2,001)$.

\section{Limitations of the Data}

IPV-related incident data collected for the current study were based on incidents that became known to and were recorded by law enforcement agencies in the years 2004-2007. Some agencies could not provide data for all four years; however, given that the outcome variable (described below) is not reliant on complete incident counts, this is not considered problematic for this study. Dependent on the filing methods of local law enforcement agencies, incident reports were either hand-written or data was imputed electronically by varying individual officers and/or data entry clerks. Therefore, the data were subject to irregularity and human error. Inconsistencies include (but are not limited to) coding incident form fields incorrectly, leaving them blank, writing illegibly and making incorrect inferences about the relationship between the victim and offender if not otherwise stated.

\section{Incident Variables}

Incident-level variables include age and dummy indicators for the race and sex of both suspects and victims, the type of premise where the incident occurred, and victim/offender relationship type. Premise type was coded dichotomously, meaning the incident either happened at (0) a residence or (1) a non-residence. Due to the focus on weapon use, we included demographic characteristics of suspects only in the multivariate analyses. Suspect age is measured in years based on date of birth recorded in the incident report. Given a relatively large frequency of missing data on this variable ( $\mathrm{n}=259)$, we imputed suspect's age as the victim's age where suspect age was not recorded, assuming a substantial degree of age homophily in intimate relationships. ${ }^{5}$ In cases where suspect sex was not recorded, rather than an imputation we included a dummy indicator variable in the multivariate model for missing values. The nature of the relationship between victim and suspect was coded as spouse, dating/cohabiting, ex-intimate (i.e., ex-spouse or ex-dating) or unknown intimate. The unknown intimate category was found to exist in some of the cases where the victim and offender were known to be domestically related at the time of the incident, but the exact relationship was not explicitly stated.

Weapons were coded originally into six categories: firearm, knife, blunt object, personal (hands, feet, fist, etc.), other ${ }^{6}$, and none/unknown. The outcome variable in the multivariate 
analyses, weapon use, is a binary variable that is equal to 1 if the incident involved a firearm, knife, or blunt object, and 0 otherwise.

\section{Social Isolation}

At the tract level, our proxy measure for social isolation is the concentration of poverty in the census tract. Poverty concentration assesses the degree to which the poor in each tract are socially isolated. We use block-group data to calculate the isolation index (Massey and Denton 1988; Lee 2008).

$$
x P * x=\sum_{i=1}^{n}\left[x_{i} / X\right]\left[x_{i} / t_{i}\right]
$$

where $x_{i}$ refers to the number of individuals in poverty (i.e., individuals earning an annual income less than the national poverty standard) that live in block group $i, X$ is the total number of poor individuals living in the tract, and $t_{i}$ refers to the total population of block group $i$. For each tract, this index gives the probability that a randomly-selected individual in poverty shares a neighborhood with another randomly-drawn poor person. The index varies from 0 to 1 , with higher values indicating higher levels of poverty concentration or class-based social isolation. In the study data, the mean across the 39 areas was 0.25 , indicating an average probability of one in four ( 25 percent) that two randomly-drawn poor individuals share a block group. The block group-level data used to construct this index were taken from Summary File 3 of the 2000 Census.

\section{Firearm Prevalence}

An important control for the prevalence of weapon use in IPV incidents is the general availability of firearms in the local area (Sorenson and Wiebe, 2004; Sorenson, 2006). Because comprehensive records of firearm ownership in the U.S. are not available, previous studies have employed proxies for gun ownership by measuring the percentage of suicides in an area that were committed with a firearm (Kleck, 2004; Stults and Baumer, 2008). Using data from the state's Violent Death Reporting System, we geocoded the location of all suicides in the tricounty area that occurred between 2004 and 2007, along with an indicator for whether or not the suicide was committed using a firearm (NC-VDRS, 2012). By summing all suicides within the tract, a percentage of those committed using a firearm was calculated. Tracts with no suicides during the time period were coded as 0 ; the median prevalence of firearm-related suicides (i.e., firearm availability) was 60 percent.

\section{Analytical Strategy}

Because the data have a multilevel structure (cases within census tracts) - which might itself have an influence on the nature of IPV across these three rural counties - we chose to use multilevel techniques to estimate the logistic regression model estimating the probability of weapon presence in IPV incidents. The methodological rationale for this decision is that the 
Social Isolation and Weapon Use in Intimate Partner Violence Incidents in Rural Areas - Maume, Lanier, Hossfeld, and Wehmann

traditional maximum likelihood techniques used in estimating logistic regression are unacceptable for multilevel analyses because they tend to inefficiently estimate the effects of structural-level predictors. Multilevel models are likely to produce more accurate estimates of the standard errors of, in this case, tract-level coefficients, and reduce the chances of Type I errors in hypothesis testing (Bryk and Raudenbush, 1992; Wang, Xie and Fisher, 2012). Multilevel modeling allows for estimating the between- and within-group variance components of the mean outcome (intercept) assumed to vary between tracts. The theoretical rationale is based on the hypothesis that IPV weapon prevalence varies not only by situational factors, but by structural factors measured at the tract level, namely social isolation. All multilevel analyses were done using PROC GLIMMIX in SAS 9.2 (Wang et al, 2012). Listwise deletion of missing data produced a dataset of 1,981 incidents within 39 census tracts, for an average of 50 incidents per tract.

\section{Results}

Table 2 presents descriptive statistics for all incident-level variables in the dataset, along with a subset of statistics for incidents where a weapon (firearm, knife/cutting instrument, blunt object, or other) was used. The last column in the table indicates the statistical significance of the bivariate association between each categorical independent variable involving either suspect, relationship, or various situational characteristics and the binary dependent variable (weapon/no weapon used).

Beginning with the breakdown of incidents by weapon use and type at bottom of the table, it is noteworthy that less than 2 percent of the incidents in the study data involved use of a firearm. The most prevalent weapon (6.8\% of all incidents) was a blunt object, such as a hammer, broom handle, pipe, rock, or brick. By far the majority of incidents (66.3\%) involved use of hands (hitting, slapping, punching) or feet (kicking, stomping) by the attacker.

As expected, suspect and victim demographic characteristics are similar with regard to race/ethnicity and age, but males are over-represented as suspects and under-represented as victims in these incidents. Approximately 80 percent of the incidents involved a male suspect, and not quite 17 percent involved a male victim. The statistically significant relationship between weapon use and suspect sex $\left(\chi^{2}=73.8, \mathrm{p}<.001\right)$ indicates that female suspects were more prevalent in incidents where a weapon was used (29.5\%) than in the overall sample (14.8\%). This finding mirrors other studies that have found a higher rate of weapon use among women than men in IPV incidents (Kernsmith and Craun, 2008; Cho and Wilke, 2010).

Findings for race/ethnicity indicate that Native Americans are over-represented in weaponrelated IPV incidents as both suspects and victims compared to their representation in all incidents, whereas whites are underrepresented and African-Americans are slightly underrepresented as suspects and slightly over-represented as victims in IPV incidents where a weapon 
International Journal of Rural Criminology, Volume 2, Issue 2 (June), 2014

Table 2: IPV Incident Data Descriptive Statistics $(n=2,001)$

\begin{tabular}{|c|c|c|c|c|c|c|}
\hline Variable & \multirow[t]{2}{*}{ Percent } & \multirow[t]{2}{*}{ (n) } & \multicolumn{2}{|c|}{$\begin{array}{c}\text { Weapon used } \\
(\mathrm{N}=349)\end{array}$} & \multirow[t]{2}{*}{$\begin{array}{c}\text { Chi- } \\
\text { square }\end{array}$} & \multirow[t]{2}{*}{ (prob) } \\
\hline Suspect & & & & & & \\
\hline Sex & & & & & 73.8 & $(<.001)$ \\
\hline Male & 79.7 & $(1,594)$ & 64.5 & $(225)$ & & \\
\hline Female & 14.8 & $(297)$ & 29.5 & (103) & & \\
\hline Unknown & 5.5 & $(110)$ & 6.0 & $(21)$ & & \\
\hline Race & & & & & 11.7 & $(<.01)$ \\
\hline Black & 41.5 & $(831)$ & 39.0 & $(136)$ & & \\
\hline Native Amer. & 15 & $(301)$ & 20.6 & $(72)$ & & \\
\hline White & 32.5 & $(650)$ & 28.7 & $(100)$ & & \\
\hline Other & 10.9 & (219) & 11.8 & $(41)$ & & \\
\hline \multicolumn{7}{|l|}{ Age } \\
\hline Mean (SD) & 33.8 & $(11.0)$ & 35.6 & (11.4) & & \\
\hline \multicolumn{7}{|l|}{ Victim } \\
\hline \multicolumn{7}{|l|}{ Sex } \\
\hline Male & 16.9 & $(339)$ & 33.0 & $(115)$ & & \\
\hline Female & 82.7 & $(1,655)$ & 67.1 & $(234)$ & & \\
\hline Unknown & 0.4 & (7) & 0.0 & $(0)$ & & \\
\hline \multicolumn{7}{|l|}{ Race } \\
\hline Black & 40.1 & $(803)$ & 43.0 & $(150)$ & & \\
\hline Native Amer. & 17.8 & (357) & 20.9 & $(73)$ & & \\
\hline White & 39.8 & (797) & 33.2 & (116) & & \\
\hline Other & 2.2 & $(44)$ & 2.9 & $(10)$ & & \\
\hline \multicolumn{7}{|l|}{ Age } \\
\hline Mean (SD) & 33.2 & $(11.0)$ & 35.1 & $(11.1)$ & & \\
\hline Relationship type & & & & & 8.98 & $(<.05)$ \\
\hline Spouse & 31.2 & $(623)$ & 30.1 & $(105)$ & & \\
\hline Dating/cohabiting & 55.1 & (1100) & 51.6 & $(180)$ & & \\
\hline Ex-intimate & 11.6 & $(232)$ & 14.9 & $(52)$ & & \\
\hline Unknown & 2.1 & $(41)$ & 3.4 & $(12)$ & & \\
\hline Premise type & & & & & 0.19 & $(0.67)$ \\
\hline Residence & 87.2 & $(1,745)$ & 88.0 & $(307)$ & & \\
\hline Other & 12.7 & $(259)$ & 12.0 & $(42)$ & & \\
\hline \multicolumn{7}{|l|}{ Weapon } \\
\hline Firearm & 1.8 & $(35)$ & & & & \\
\hline Knife/cutting instrument & 3.8 & $(75)$ & & & & \\
\hline Blunt object & 6.8 & $(136)$ & & & & \\
\hline Personal & 66.3 & $(1,324)$ & & & & \\
\hline Other & 5.2 & $(103)$ & & & & \\
\hline None/unknown & 16.2 & $(324)$ & & & & \\
\hline
\end{tabular}


Social Isolation and Weapon Use in Intimate Partner Violence Incidents in Rural Areas - Maume, Lanier, Hossfeld, and Wehmann

was used. Overall, suspect race/ethnicity is significantly associated with weapon use in IPV incidents $\left(\chi^{2}=11.7, \mathrm{p}<.01\right)$, although the finding is statistically weaker compared to the previous association described between suspect sex and weapon use.

Weapon use is more prevalent in incidents involving ex-intimate partners $\left(\chi^{2}=8.98, \mathrm{p}<\right.$ $.05)$. No statistically significant difference in weapon use/non-use was found based on the location of the incident.

To assess the likelihood of IPV incidents involving use of a weapon, we estimated a multivariate logistic regression model (see Table 3). The overall model compares the likelihood of an incident involving a weapon versus not. Akin to a standard logistic regression analysis, at the incident level the model estimates the (log) odds that an incident will involve a weapon given a set of incident-level and tract-level covariates. The tract level the model is predicting the adjusted mean prevalence, or likelihood, of IPV weapon use for each tract, controlling for the other predictors in the model. All of the incident-level variables were treated as fixed effects, meaning that their relationships with the dependent variable were not assumed to vary between counties.

Table 3: Multilevel Logistic Regression Model of Weapon Use in IPV incidents (1,981 incidents; 39 tracts)

\begin{tabular}{lccccc} 
Variables in the Equation & & & & & \\
& B & S.E. & t & Odds & \\
\hline Intercept & -2.45 & 0.62 & -3.93 & & \\
$\quad$ Tract isolation & -1.27 & 1.75 & -0.73 & 0.28 & \\
$\quad$ Tract firearm access & 0.00 & 0.00 & 1.390 & 1.00 & \\
Suspect sex - female & 1.33 & 0.15 & 8.720 & 3.80 & $* * *$ \\
Suspect race -- Native Amer. & 0.30 & 0.20 & 1.500 & 1.35 & \\
Suspect race - White & -0.25 & 0.17 & -1.490 & 0.78 & \\
Suspect race - Other & -0.07 & 0.29 & -0.250 & 0.93 & \\
Suspect age & 0.02 & 0.01 & 3.750 & 1.02 & $* * *$ \\
Relationship type - dating & -0.01 & 0.15 & -0.090 & 0.99 & \\
Relationship type -- ex-intimate & 0.38 & 0.21 & 1.77 & 1.46 & \\
Relationship type -- unknown & 0.14 & 0.40 & 0.37 & 1.16 & \\
Premise type - residence & -0.03 & 0.20 & -0.14 & 0.97 &
\end{tabular}

Random effects significance test (intercept): -2 RPL $=9946.11$,

Chi-square $=47.09, p<.0001$

* Model includes coefficient for missing suspect sex (coefficient not shown) 
As shown in Table 3, there are only two significant fixed effects amongst the incident-level covariates on the prevalence of IPV weapon use. Compared to males, female suspects were more likely to have used a weapon in the IPV incident. There is a statistically significant association between suspect age and weapon use; the odds ratio indicates that, controlling for the other variables in the model, the odds of using a weapon increase by 2 percent with each increment in suspect age. Other than suspect sex and age, there are no other coefficients that come close to achieving statistical significance.

Based on a preliminary empty model assessing variance in the outcome variable, we determined that approximately 11 percent of the variance in IPV weapon use was composed of between-tract variation in the outcome, and that this random variation was statistically significant (Model $\chi^{2}=47.09, \mathrm{p}<.0001$; findings not shown). In the portion of the multilevel model estimating the intercept (i.e., mean prevalence of IPV weapon use) across level two units (i.e., tracts), we see that neither the tract-level predictor of main interest, social isolation, nor the control for firearm access achieved statistical significance. Although statistical power may have been an issue with only 39 tracts, by limiting level-two estimation to only two covariates we suspect that power was not a problem in this analysis. Indeed, in alternative models specifying only social isolation in the one and firearm availability in the other, neither variable's log odds coefficient was statistically significant.

\section{Discussion and Conclusion}

Although nationally representative data indicate IPV prevalence rates that are similar across urban and rural areas, as many observers have noted, the nature and seriousness of IPV across the rural-urban continuum has been found to vary (Jennings and Piquero, 2008; GallupBlack, 2005; Orchowsky, 1998; Logan et al, 2003). The purpose of this study was to assess the nature of IPV in rural southeastern North Carolina; specifically, the prevalence of weapon use in violent intimate-partner incidents in three rural counties, and factors that may explain such use. Based on an analysis of 1,981 incidents, we found that the only statistically significant predictors of weapon use were gender and age. Women were more likely than their male partners to use a weapon in the reported incident, as were older individuals.

In most cases, such gender differences signify a weapon employed by women either as a means to compensate for men's relative physical size and strength, or as an object to resist or defend men's attacks, or both. Johnson's (2008) typology of domestic violence is another attempt to explain IPV based on its nature and context. He has argued that much of the incidence of IPV that is reported from survey data is what could be called common couple violence, which is characterized by episodic bouts of abuse in which both the male and female partner are perpetrators of violence. This is to be distinguished from what he calls intimate terrorism, which emphasizes the coercive control by one partner over the other in an ongoing manner that tends to escalate in seriousness over time. Males are much more likely than females to be the aggressors 
Social Isolation and Weapon Use in Intimate Partner Violence Incidents in Rural Areas - Maume, Lanier, Hossfeld, and Wehmann

in this type of IPV, and in fact when female partners use violence, it may be characterized in Johnson's typology as violent resistance, or violence used in direct response to the male partner's aggression in the situation or the relationship. It is this last category that may be shed light on our findings. Miller's (2005) study of women involved in IPV revealed that the majority of those in her sample of women who were arrested for an IPV incident and sentenced to treatment - whilst readily admitting their use of violence — were overwhelmingly likely to have resorted to violence in response to a battering partner. Miller (2005, p. 121) relates the following account from a woman who faced twenty-five years in prison for assault, but pled guilty and was sentenced to a female offender's program for domestic violence:

I tried to leave but he doesn't want me to leave, but I walked out the door and he jumps on me. I hopped in my car, and he moves behind my car and in front of my car and tries to break into the windows with a stick. So I tried to put my car in drive and pinned him up against the garage wall. I didn't realize what I was doing until he looked at me and said, "Patty, please go." I felt like total shit, I put my car in reverse and just left.

Miller (2005, p. 66) also found that women are more likely than men to use weapons in instances where they are attempting to "equalize the force between them and male combatants, which often means a kitchen object such as a knife, pan, glass, or dish." In a recent quantitative analysis of IPV incidents using NIBRS data, it was found that male victims were 11 times more likely than female victims to be attacked with a weapon than with hands or feet (Addington and Perumean-Chaney, 2013). Although not a direct test of Johnson's typology, the authors of this study concluded that women's use of weapons in IPV incidents might suggest violent resistance. Thus, both the use of violence in general and the employment of weapons in intimate relationships appears to be highly gendered, and may also intersect with race and class to produce qualitative differences (Richie, 1996). Further research using multiple sources of data is needed to contextualize weapon use in IPV incidents amongst women, as well as men (Ferraro, 2013).

There are some limitations to the current study. First, and directly related to the immediately preceding discussion, we had access to the data on the current incidents, which prevented us from putting the IPV incident into a context that could have documented a history of IPV incidents and arrests amongst intimate partners. Even in the current incident it is not possible to identify to what extent the violence may have been employed for purposes of selfdefense, relief from an abusive batterer (Miller 2005), retaliation, or vengeance (Phillips 2002). This makes it difficult to do more than speculate on how IPV weapon use fits in with existing domestic violence typologies. Second, our data relied on the reporting officers' recounting of the incident in the official reports, which implies the possibility of bias in terms of underreporting or incomplete reporting of the events that occurred. ${ }^{7}$ This issue may be particular salient in rural areas, as some have suggested "...the patriarchal attitudes of rural police officers and the way in which these attitudes mitigate against a timely and effective response to domestic calls" as 
prevalent in these locales (Websdale, 2002: 84; see also Few, 2005). In addition, as noted by Warner (2010, p.192), "one may argue that because the violence was serious enough to draw police attention, police-based agency data are biased towards the most severe form of IPV, intimate terrorism," but she goes on to add that "given the use of control motives by intimate terrorists (necessary to distinguish the violence as intimate terrorism) and victim fearfulness, it seems somewhat unlikely that victims of intimate terrorism would notify the police" (but see also Melton and Belknap, 2003, who came to the opposite conclusion). Moreover, while there is much evidence to suggest that underreporting directly affects rates of IPV or violence in general, there is less to suggest that such underreporting seriously biases the prevalence of weapon use in IPV incidents.

Although our study seems to provide few avenues for intervention in IPV weapon use, we are not alone in this dilemma. In a brief assessment of evaluation studies designed to assess the effectiveness of IPV interventions, Spohn (2008, p. 489) notes that "although some exceptions exist, most of these studies concluded that the criminal justice interventions being evaluated did not deter IPV offenders or improve victim safety." The implication is that more should be done to focus on preventing IPV incidents from occurring, with an emphasis on involving the community in such efforts as building social capital and enhancing collective efficacy (Mancini, Nelson, Bowen and Martin, 2006). Nevertheless, this does not mean that intervention efforts should be abandoned. As noted at the outset of the study, there have been relatively few studies addressing the nature of IPV in rural contexts, and efforts to address IPV in rural areas must take the character of such contexts into account. For example, in a study of the use of civil protection orders to reduce IPV incidents in rural Kentucky, Logan and Walker (2011) reported that women reported fewer IPV incidents after receiving a protection order. The "weak link" in this association, they noted, was the enforcement of such orders in rural areas characterized by isolation, a lack of enforcement resources, and a lack of enforcement due to political and social ties in rural communities. In addition, future quantitative or mixed-method research should focus not only on the extent of IPV across various contexts, but should seek to differentiate IPV incidents based on their qualitative aspects. One example of a mixed-methods approach that has explicitly acknowledged context is a study published by Burke and colleagues (2006) which used a participatory research method known as "concept mapping." Their research design used samples of urban and suburban women involved in "brainstorming" efforts to identify and both qualitatively and statistically formulate clusters of neighborhood-level correlates of IPV persistence and desistance. Such mixed methods could be applied in rural areas, and used to focus efforts to collect neighborhood-level quantitative measures that might be specifically relevant to the nature and extent of IPV in rural communities, including weapon use. A recent fact sheet published by the U.S. White House (2013) has drawn specific attention to the role of firearms in domestic violence homicides. Such attention at the federal level should spur further and more innovative weapons-related IPV research. 


\section{Endnotes}

${ }^{1}$ The research reported here was supported by a Cahill grant from UNC Wilmington. We would like to thank all participating law enforcement agencies in Bladen, Columbus, and Robeson counties and staff at Southern Software, Inc. for their cooperation and assistance in acquiring the data necessary for this project. We would like to thank the NC Violent Death Reporting System (VDRS) staff, particularly Scott Proescholdbell, for providing access to VDRS suicide data, as well as the contributing agencies to the VDRS (NC Office of the Chief Medical Examiner, State Bureau of Investigation, and local law enforcement agencies). We would also like to thank Robert Hicks, Amy Mills, and Lindsey Martin Silverberg for their research assistance.

${ }^{2}$ Interestingly, while gun ownership in the United States is relatively high compared to other nations, with about one-third of U.S. households reporting owning at least one firearm, ownership rates vary widely by region and rurality (Cook et al. 2000). Although particularly high in rural areas, firearms - especially long guns_-are more likely to be used for sport (hunting, target shooting) than resolving violent conflicts (Kovandzic et al. 2013), and Weisheit and Donnermeyer (2000) note that the use of firearms in rural areas in criminal activity is lower than urban areas.

${ }^{3}$ Originally, 4 counties were selected, but access to incident records in the fourth county was denied by the county sheriff's office due to filing issues and confidentiality concerns.

${ }^{4}$ Each agency was asked to provide all misdemeanor and felony incidents relating to assaults of any nature, sexual offenses, and homicides in which the victim and offender are or were intimately involved at the time of the offense. Agencies were selected based on the size of the communities they serve and their annual aggravated and simple assault counts from the NC State Bureau of Investigation's crime statistics website. Unlike police and sheriff departments in large urban jurisdictions, most of the rural agencies in the study area still relied solely on paper files to preserve incident and arrest reports. Seven agencies were visited by a team of research assistants who read each incident report to determine if it was IPV-related. All IPV reports were scanned and coded by the research team. In some cases, agency staff was on hand to clarify notation used by the recording officers. The research team was able to remotely (electronically) access the incident report databases of the remaining six agencies with the assistance of their public safety software vendors. Data obtained electronically were formatted in Excel and only cases where an intimate relationship was identified were retained.

${ }^{5}$ The average difference in age between suspects and victims in the dataset was 0.9 , or slightly less than a year (victims being younger on average than suspects). Although the distribution of cases clustered closely around the mean $(\mathrm{SD}=7.73, \mathrm{IQR}=7.15)$, the extremes at the tails were 41-year age differences in both directions. 
${ }^{6}$ Other weapons included items such as motor vehicles, rubber hoses, tools (e.g., screwdriver), and, in a few cases, hot grease.

${ }^{7}$ North Carolina law follows other states in specifying mandatory arrest policy if there is visible physical injury. Dual arrests are allowed when the officers perceive that both parties in the domestic incident caused physical harm to one another without provocation (i.e. not as a result of self-defense). Although all police officers receive training on responding to domestic violence incidents, only one of the agencies that provided data for the study had the resources to support specialized domestic response training for their officers (and at that time, only two officers had received such training). 
Social Isolation and Weapon Use in Intimate Partner Violence Incidents in Rural Areas - Maume, Lanier, Hossfeld, and Wehmann

\section{References}

Addington, L. A., \& Perumean-Chaney, S.E. (2013). Fatal and non-fatal intimate partner violence: What separates the men frrom the women for victimizations reported to police? Forthcoming, Homicide Studies.

Benson, M. L., Fox, G.L., \& DeMaris, A. (2003). Neighborhood disadvantage, individual economic distress and violence against women in intimate relationships. Journal of Quantitative Criminology, 19, 207-235.

Brennan, I. R. \& Moore, S.C. (2009). Weapons and violence: A review of theory and research. Aggression \& Violent Behavior, 14, 215-225.

Browning, C. R. (2002). The span of collective efficacy: Extending social disorganization theory to partner violence. Journal of Marriage and Family, 64, 833-850.

Bryk, A. S. \& Raudenbush, S.W. (1992). Hierarchical linear models: Applications and data analysis methods. Newbury Park, CA: SAGE.

Burke, J. G., O' Campo, P., \& Peak, G.L. (2006). Neighborhood influences and intimate partner violence: Does geographic setting matter? Journal of Urban Health, 83, 182-194.

Bursik, R. J., Jr. (1988). Social disorganization and theories of crime and delinquency: Problems and prospects. Criminology, 26, 519-51.

Buzawa, E. S. (2003). Domestic violence: The criminal justice response ( $3^{\text {rd }}$ ed.). Thousand Oaks, California: Sage.

Capaldi, D. M., Shortt, J.W., Kim, H.K., Wilson, J., Crosby, L., \& Tucci, S. (2009). Official incidents of domestic violence: Types, injury, and associations with nonofficial couple aggression. Violence and Victims, 24, 502-519.

Capaldi, D.M., Knoble, N.B., Shortt, J.W., \& Kim, H.K. (2012). A systematic review of risk factors for intimate partner violence. Partner Abuse, 3, 231-280.

Centers for Disease Control and Prevention. (2008). National Violent Death Reporting System (NVDRS) coding manual revised [Online]. National Center for Injury Prevention and Control, Centers for Disease Control and Prevention (producer). Available from URL: www.cdc.gov/injury. 
Cho, H., \& Wilke, D.J. (2010). Gender differences in the nature of intimate partner violence and effects of perpetrator arrest on revictimization. Journal of Family Violence, 25, 393-400.

Cook, P. J., Braga, A. A., \& Moore, M.H. (2000). Gun control. In J.Q. Wilson and J. Petersilia (eds.), Crime and Public Policy (pp. 257-292). Oxford: Oxford University Press.

DeKeseredy, W S. and Joseph, C. (2006). Separation and/or divorce sexual assault in rural Ohio: Preliminary results of an exploratory study. Violence Against Women, 12, 301-311.

DeKeseredy, W. S. \& Schwartz, M.D. (2009). Dangerous exits: Escaping abusive relationships in rural America. New Brunswick: Rutgers University Press.

DeKeseredy, W. S., Dragiewicz, M., \& Rennison, C.M. (2012). Racial/ethnic variations in violence against women: Urban, suburban, and rural differences. International Journal of Rural Criminology, 1, 184-202.

DeKeseredy, W. S., Donnermeyer, J.F., Schwartz, M.D., Tunnell, K.D., \& Hall, M. (2007). Thinking critically about rural gender relations: Toward a rural masculinity crisis/male peer support model of separation/divorce sexual assault. Critical Criminology, 15, 295311.

Eastman, B. J., S. G. Bunch, et al. (2007). Exploring the perceptions of domestic violence service providers in rural localities. Violence Against Women, 13, 700-716.

Ferraro, K. (2013). Gender matters in intimate partner violence. In B.L. Russell (ed.), Perceptions of female offenders: How stereotypes and social norms affect criminal justice responses (pp. 133-149). New York: Springer.

Few, A. L. 2005. The voices of black and white rural battered women in domestic violence shelters. Family Relations, 54, 488-500.

Feyen, C. (1989). Battered rural women: An exploratory study of domestic violence in a Wisconsin County. Wisconsin Sociologist, 26, 17-32.

Folkes, S. E., Hilton, N. Z., \& Harris, G.T. (2013). Weapon use increases the severity of domestic violence but neither weapon use nor firearm access increases the risk or severity of recidivism. Journal of Interpersonal Violence, 28, 1143-1156.

Gallup-Black, A. (2005). Twenty years of rural and urban trends in family and intimate partner homicide: Does place matter. Homicide Studies, 9, 149-173. 
Social Isolation and Weapon Use in Intimate Partner Violence Incidents in Rural Areas - Maume, Lanier, Hossfeld, and Wehmann

Geissinger, C. J., Lazzari, M. M., Porter, M. J., \& Tungate, S.L. (1993). Rural woman and isolation: Pathways to reconnection. Affilia: Journal of Women \& Social Work, 8, 277 299.

Goeckermann, C. R., Hamberger, L. K., \& Barber K. (1994). Issues of domestic violence unique to rural areas. Wisconsin Medical Journal, 93, 473-479.

Guzmán, B. (2001). The Hispanic population: Census 2000 brief. Washington, D.C.: U.S. Census Bureau.

Hossfeld, L, Legerton, M., \& Keuster, G. (2004). The economic and social impact of job loss in Robeson County, North Carolina. Sociation Today, 2, [np]. URL: http://www.ncsociology.org/sociationtoday/outline1.htm

Jennings, W. G., \& Piquero, A.R. (2008). Trajectories of non-intimate partner and intimate partner homicides, 1980-1999: The importance of rurality. Journal of Criminal Justice, $36,435-443$.

Johnson, M. P. (2008). A typology of domestic violence: Intimate terrorism, violent resistance, and situational couple violence. Boston: Northeastern University Press.

Kernsmith, P., \& Craun, S.W. (2008). Predictors of weapon use in domestic violence incidents reported to law enforcement. Journal of Family Violence, 23, 589-96.

Kleck, G. (2004). Measures of gun ownership levels for macro-level crime and violence research. Journal of Research in Crime and Delinquency, 41, 3-36.

Kovandzic, T., Schaffer, M.E., \& Kleck, G. (2013). Estimating the causal effect of gun prevalence on homicide rates: A local average treatment effect approach. Journal of Quantitative Criminology, 29, 477-541.

Krieger, N., Zierler S., Hogan, J. W., Waterman, P., Chen J., Lemieux, K., \& Gseljvik, A. (2003). Geocoding and measurement of neighborhood socioeconomic position: A U.S. perspective. In I. Kawachi \& L.F. Berkman (eds.), in Neighborhoods and health (pp. 147178). Oxford: Oxford University Press.

Krishnan, S. P., Hilbert, J.C, \& VanLeeuwen, D. (2001). Domestic violence and help-seeking behaviors among rural women: Results from a shelter-based study. Family Community Health, 24, 28-38. 
Lanier, C., \& Maume, M.O. (2009). Intimate partner violence and social isolation across the rural/urban divide. Violence Against Women, 15, 1311-1330.

Lee, M. R. (2008). Civic community in the hinterland: Toward a theory of rural social structure and violence. Criminology, 46, 447-478.

Lee, M. R., Maume, M.O., Ousey, G.C. (2003). Social isolation and lethal violence across the metro/nonmetro divide: The effects of socioeconomic disadvantage and poverty concentration on homicide. Rural Sociology, 68, 107-131.

Li, Q., Russell S. K., Sigler, R. T., Hwang. S. S., LaGory, M.E., \& Goldenberg, R.L. (2010). A multilevel analysis of individual, household, and neighborhood correlates of intimate partner violence among low-income pregnant women in Jefferson County, Alabama. American Journal of Public Health, 100, 531-539.

Logan, T.K., \& Walker, R. (2011). Civil protective order effectiveness in rural and urban Areas: The role of place in the justice system response to partner violence. Carsey Policy Paper. http://www.carseyinstitute.unh.edu

Logan, T.K., Walker, R., Cole, J., Ratliff, S., \& Leukefeld, C. (2003). Qualitative differences among rural and urban intimate violence victimization experiences and consequences: A pilot study. Journal of Family Violence, 18, 83-92.

Mancini, J A., Nelson, J.P., Bowen, G.L., \& Martin, J. A. (2006). Preventing intimate partner violence: A community capacity approach. In S. M. Stith (ed.), Prevention of intimate partner violence (pp. 203-227). New York: Haworth.

Massey, D. S., \& Denton, N. A. (1988). The dimensions of residential segregation. Social Forces, 67, 281-315.

Melton, H. C., \& Belknap, J. (2003). He hits, she hits: Assessing gender differences and similarities in officially reported intimate partner violence. Criminal Justice and Behavior, 30, 328-348.

Messer, L. C., Laraia, B. A., Kaufman, J. S., Eyster, J., Holzman, C., Culhane, J., Elo, I., Burke, J.G., \& O'Campo, P. (2006). The development of a standardized neighborhood deprivation index. Journal of Urban Health, 83, 1041-1062. 
Social Isolation and Weapon Use in Intimate Partner Violence Incidents in Rural Areas - Maume, Lanier, Hossfeld, and Wehmann

Miles-Doan, R. (1998). Violence between spouses and intimates: Does neighborhood context matter? Social Forces, 77, 623-645.

Miller, S. L. (2005). Victims as offenders: The paradox of women's violence in relationships. New Brunswick, NJ: Rutgers University Press.

NC-VDRS (2012). The North Carolina Violent Death Reporting System (N.C. VDRS). Retrieved from http://www.injuryfreenc.ncdhhs.gov/About/ncVDRS.htm.

Olson, C. S. (1988). Blue Ridge blues: The problems and strengths of rural women. Affilia: Journal of Women \& Social Work, 3, 5-18.

Orchowsky, S. (1998). The unique nature of domestic violence in rural areas. JRSA Forum, 16, 1 \& 6-9.

Osgood D. W., \& Chambers, J.M. (2000). Social disorganization outside the metropolis: An analysis of rural youth violence. Criminology, 38, 81-115.

Peterson, R. D., Krivo, L. J., \& Harris, M. A. (2000). Disadvantage and neighborhood violent crime: Do local institutions matter? Journal of Research in Crime and Delinquency, 37, $31-63$.

Phillips, S. (2002). The social structure of vengeance: A test of Black's model. Criminology, 41, 673-708.

Phillips, S., \& Maume, M.O. (2007). Have gun will shoot? Weapon instrumentality, intent, and the violent escalation of conflict. Homicide Studies, 11, 272-294.

Pinchevsky G. M., \& Wright, E.M. (2012). The impact of neighborhoods on intimate partner violence and victimization. Trauma, Violence \& Abuse, 13, 112-32.

Richie, B. E. (1996). Compelled to crime: The gender entrapment of battered black women. London: Routledge.

Sampson, R. J., \& Groves, W.B. (1989). Community structure and crime: Testing socialdisorganization theory. American Journal of Sociology, 94, 774-802.

Sampson, R. J., Raudenbush, S., \& Earls, F. (1997). Neighborhoods and violent crime: A multilevel study of collective efficacy. Science, 277, 918-24. 
Schaffer, J. (1999). Older and isolated women and domestic violence project. Journal of Elder Abuse \& Neglect, 11, 59-77.

Shuman, R. D., McCauley, J., Waltermaurer, E., Roche, W.P., Hollis, H., Kilgannon, A., Denver, A., Solita, J., \& McNutt, L. A. (2008). Understanding intimate partner violence against women in the rural south." Violence and Victims, 23, 390-405.

Sorenson, S. B. (2006). Firearm use in intimate partner violence: A brief overview. Evaluation Review, 30, 229-236.

Sorenson, S. B., \& Wiebe, D. J. (2004). Weapons in the lives of battered women. American Journal of Public Health, 94, 1412-1417.

Stults, B. J., \& Baumer, E.P. (2008). Assessing the relevance of anomie theory for explaining spatial variation in lethal criminal violence: An aggregate-level analysis of homicide within the United States. International Journal of Conflict and Violence, 2, 215-247.

Teaster, P. B., Roberto, K. A., \& Dugar, T. A. (2006). Intimate partner violence of rural aging women. Family Relations, 55, 636-648.

Thomas, S. A. (2009). Beyond crime quantities: A multilevel analysis of the relative prevalence of interracial violence. Unpublished Ph.D. dissertation.

Triplett, R. A., Gainey, R. R., \& Sun, I. Y. (2003). Institutional strength, social control, and neighborhood crime rates. Theoretical Criminology, 7, 439-467.

U.S. Census Bureau. (2001). Census 2000 summary file 1: Technical documentation. Washington, D.C.: U.S. Census Bureau.

U.S. Department of Agriculture, Economic Research Service. (2013). Persistent-poverty counties are mostly nonmetro, generally southern. URL: www.ers.usda.gov/data-products/chartgallery/detail.aspx?chartId=38238 (Accessed on January 13, 2014).

Wang, J., Haiyi X., \& Fisher, J. H. (2012). Multilevel models: Applications using SAS. Berlin: de Gruyter.

Warner, T. (2010). Violent acts and injurious consequences: An examination of competing hypotheses about intimate partner violence using agency-based data. Journal of Family Violence, 25, 183-193. 
Social Isolation and Weapon Use in Intimate Partner Violence Incidents in Rural Areas - Maume, Lanier, Hossfeld, and Wehmann

Websdale, N. (2002). Rural woman battering and the justice system: An ethnography. Thousand Oaks, California: SAGE.

Websdale, N., \& Johnson, B. (1998). An ethnostatistical comparison of the forms and levels of woman battering in urban and rural areas of Kentucky. Criminal Justice Review, 23, 161196.

Weisheit, R. A., \& Donnermeyer, J.F. (2000). Change and continuity in crime in rural America. In G. LaFree, J. F. Short, R. J. Bursik, Sr., \& R. B. Taylor (Eds.), The nature of crime: Continuity and change. Criminal justice 2000 Volume 1 (pp. 309-348). Washington, D.C.: National Institute of Justice.

Wells, W., \& Horney, J. (2002). Weapon Effects and Individual Intent to do harm: Influences on the Escalation of Violence. Criminology, 40, 265-296.

White House, The. (2013). The link between common sense efforts to reduce gun violence and preventing domestic violence homicides. [Factsheet] URL: http://www.whitehouse.gov/sites/default/files/docs/dv_homicide_reduction_and_guns_fa ct_sheet.pdf

Wilkinson, D. L., \& Hamerschlag, S.J. (2005). Situational determinants in intimate partner violence. Aggression \& Violent Behavior, 10, 333-361. 